\title{
Radiologically isolated syndrome in children
}

Can we predict future events? OPEN
E. Ann Yeh, MD, MA, FRCP(C)

Correspondence to

Dr. Yeh:

ann.yeh@sickkids.ca

Neurol Neuroimmunol

Neuroinflamm

2017;4:e411; doi: 10.1212/

NXI.0000000000000411
The phenomenon of radiologically isolated syndrome (RIS) in MS represents a key topic of clinical significance. Adults with RIS are asymptomatic at the time of presentation, but have brain MRI scans containing incidental findings highly suggestive of MS, and, importantly, a high rate — 59\% — of subsequent emergence of new MRI changes ${ }^{1}$ and a 5-year risk of clinical events of $34 \% .^{2}$ Of note, almost $10 \%$ of patients with RIS who experienced clinical events received a diagnosis of primary progressive MS in one study. ${ }^{2}$ Given the high rate of emergence of new neurologic abnormalities in this population, it is prudent to identify groups in which this phenomenon might exist and to clarify their future risk of relapse.

While the phenomenon has been well described in the adult population, previous studies have not documented its presence in youth. Indeed, a nationwide study in Sweden evaluating all MRI scans performed at a single institution found no children with RIS in the selected year of 2001 and a prevalence of RIS of $0.05 \% .{ }^{3}$ However, while rare, this phenomenon does exist in children, and important clinical consequences are associated with these radiologic findings. In this edition of Neurology ${ }^{\circledR}$ Neuroimmunology \& Neuroinflammation, Makhani et al. $^{4}$ describe a cohort of youth with RIS and evaluate potential predictors of future and ongoing disease activity. The authors present a cross-national retrospective case series (16 tertiary centers in the United States, Turkey, France, Argentina, Spain, and the United Kingdom) of 38 children who satisfied the 2010 McDonald dissemination in space (DIS) criteria for MS, but were asymptomatic at the time of the MRI scan; followup was a median of almost 5 years. Notably, as with their adult counterparts, the youth included in this study had a high likelihood of developing clinical events $(42 \%)$ and future development of new lesions on MRI (61\%). They experienced these events within 1-2 years of initial scan, suggesting the need for close monitoring of this cohort. Spinal cord lesions (hazard ratio $7.8,95 \%$ confidence interval $1.4-43.6, p=0.02$ ) and the presence of CSF oligoclonal bands (OBs) (hazard ratio 10.9, 95\% confidence interval 1.486.02, $p=0.02$ ) increased the risk of the development of clinical events. ${ }^{4}$

Challenges related to identifying RIS in the pediatric population are many, as asymptomatic children who satisfy the DIS criteria are potentially great in number. Approximately, $1 / 5$ of healthy youth may have incidental findings on MRI, ${ }^{5}$ with $6 \%$ in 1 population having periventricular white matter abnormalities. ${ }^{6}$ Determining which patients are in need of surveillance and which patients may have abnormalities due to one-time events in the past is, therefore, of importance. Notably, while the authors used 2010 McDonald DIS criteria to identify their cohort, their cohort was drawn from specialized MS centers. Thus, selection bias may have allowed for the inclusion of patients with images, which were most highly suggestive of MS. It is unknown whether DIS criteria, applied to a general pediatric population, will be sensitive enough to differentiate those youth with high risk of relapse from those with static lesions originating from a previous, unknown insult. Thus, future studies must focus on refining the inclusion criteria for this subgroup of patients. Limitations of the study include its retrospective nature and potential for selection bias. Importantly, however, the authors have highlighted the existence of this subgroup in the pediatric population, and that the rate of development of new lesions and clinical events may be high.

Whether identification of RIS implies a need for therapeutic intervention is an important area of controversy and future inquiry. Cross-sectional analysis of cortical involvement in adult RIS subjects has shown lower cortical volumes and mean thalamic volumes in comparison to healthy controls, as well as correlations between the white matter lesion volume and regional cortical thickness. ${ }^{7}$ The relevance of these results for pediatric cohorts has not been

From the Department of Pediatrics (Neurology), Division of Neurosciences and Mental Health, SickKids Research Institute, Hospital for Sick Children, University of Toronto, Ontario, Canada.

Funding information and disclosures are provided at the end of the editorial. Go to Neurology.org/nn for full disclosure forms. The Article Processing Charge was funded by the editorial office.

This is an open access article distributed under the terms of the Creative Commons Attribution-NonCommercial-NoDerivatives License 4. 0 (CC BY-NC-ND), which permits downloading and sharing the work provided it is properly cited. The work cannot be changed in any way or used commercially without permission from the journal. 
studied. However, multiple studies suggest the presence of degenerative biology from onset in pediatric MS, including failure of age-expected brain growth ${ }^{8}$ and a change in white matter growth trajectory after a single event. ${ }^{9}$ Furthermore, natural history studies of pediatric onset MS suggest the time of onset of secondary progression to be in the mid30s. Given this background, future studies must examine the question of the value of intervention with MS therapies at the time RIS is found in high risk youth (e.g., with positive CSF oligoclonal bands or spinal cord lesions).

Access to MRI around the world has increased significantly in the past decade. In 2014, countries such as the United States, Germany, Japan, and Turkey had rates of MRI of more than 100 per 1,000 population, ${ }^{10}$ and Canadian statistics suggest an almost doubling of MRI use between 2006 and 2014..$^{10,11}$ With it has come the inevitable rise in incidental MRI findings in asymptomatic individuals. Understanding the clinical relevance of these findings is of great importance, particularly in a phenomenon in which findings suggest the presence of a chronic, degenerative process such as MS. This phenomenon will not go away: The study by Makhani et al. emphasizes the presence of these findings in youth, and, importantly, a rate of emergence of new lesions or clinical findings equivalent to that in the adult population. How these youth should be followed and treated and how the development of sensitive criteria that can be tested more broadly are important subjects of future inquiry.

\section{STUDY FUNDING}

No targeted funding reported.

\section{DISCLOSURE}

E.A.Y. has received funds from the NMSS, CIHI, CIHR, OIRM, MS Society of Canada, Mario Battaglia Foundation, SickKids Foundation, CBMH Innovation Fund, CMSC, Rare Diseases Foundation, and Guthy Jackson Foundation. She serves as a relapse adjudicator for ACI. She has served on a scientific advisory panel for Juno Therapeutics and has received a speaker's honorarium from Novartis. Go to Neurology.org/ $\mathrm{nn}$ for full disclosure forms.

\section{REFERENCES}

1. Okuda DT, Mowry EM, Beheshtian A, et al. Incidental MRI anomalies suggestive of multiple sclerosis: the radiologically isolated syndrome. Neurology 2009;72:800-805.

2. Okuda DT, Siva A, Kantarci O, et al. Radiologically isolated syndrome: 5-year risk for an initial clinical event. PLoS One 2014;9:e90509.

3. Granberg T, Martola J, Aspelin P, Kristoffersen-Wiberg M, Fredrikson S. Radiologically isolated syndrome: an uncommon finding at a university clinic in a highprevalence region for multiple sclerosis. BMJ Open 2013;3:e003531.

4. Makhani N, Lebrun C, Siva A, et al. The radiologically isolated syndrome in children: clinical and radiological outcomes. Neurol Neuroimmunol Neuroinflamm 2018; 4:e395. doi: 10.1212/NXI.0000000000000395.

5. Kim BS, Illes J, Kaplan RT, Reiss A, Atlas SW. Incidental findings on pediatric MR images of the brain. AJNR Am J Neuroradiol 2002;23:1674-1677.

6. Potchen MJ, Kampondeni SD, Mallewa M, Taylor TE, Birbeck GL. Brain imaging in normal kids: a communitybased MRI study in Malawian children. Trop Med Int Health 2013;18:398-402.

7. Labiano-Fontcuberta A, Mato-Abad V, Alvarez-Linera J, et al. Gray matter involvement in radiologically isolated syndrome. Medicine (Baltimore) 2016;95:e3208.

8. Aubert-Broche B, Fonov V, Narayanan S, et al. Onset of multiple sclerosis before adulthood leads to failure of ageexpected brain growth. Neurology 2014;83:2140-2146.

9. Longoni G, Brown RA, MomayyezSiahkal P, et al. White matter changes in paediatric multiple sclerosis and monophasic demyelinating disorders. Brain Epub 2017 Mar 14.

10. Organization for Economic Co-operation and Development. Magnetic resonance imaging (MRI) exams [online]. Available at: https://data.oecd.org/healthcare/magneticresonance-imaging-mri-exams.htm. Accessed September 11, 2017.

11. Canadian Institute for Health Information. Medical imaging technologies in Canada, 2006-supply, utilization and sources of operating funds [online]. Available at: https:// secure.cihi.ca/free_products/mit_analysis_in_brief_e.pdf. Accessed September 11, 2017. 


\title{
Neurology \\ Neuroimmunology \& Neuroinflammation
}

\author{
Radiologically isolated syndrome in children: Can we predict future events? \\ E. Ann Yeh \\ Neurol Neuroimmunol Neuroinflamm 2017;4; \\ DOI 10.1212/NXI.0000000000000411
}

This information is current as of October 23, 2017

\section{Updated Information \& Services}

References

Permissions \& Licensing

Reprints including high resolution figures, can be found at:

http://nn.neurology.org/content/4/6/e411.full.html

This article cites 8 articles, 1 of which you can access for free at: http://nn.neurology.org/content/4/6/e411.full.html\#\#ref-list-1

Information about reproducing this article in parts (figures,tables) or in its entirety can be found online at:

http://nn.neurology.org/misc/about.xhtml\#permissions

Information about ordering reprints can be found online: http://nn.neurology.org/misc/addir.xhtml\#reprintsus

Neurol Neuroimmunol Neuroinflamm is an official journal of the American Academy of Neurology.

Published since April 2014, it is an open-access, online-only, continuous publication journal. Copyright

Copyright $\odot 2017$ The Author(s). Published by Wolters Kluwer Health, Inc. on behalf of the American

Academy of Neurology.. All rights reserved. Online ISSN: 2332-7812.

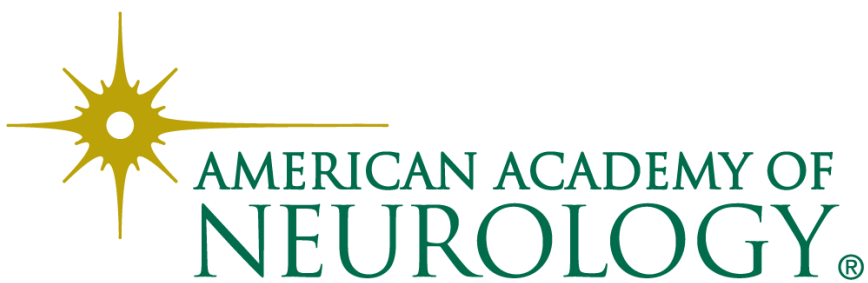

